\title{
ISOLATION, CHARACTERIZATION, AND STRUCTURE OF RABELOMYCIN, A NEW ANTIBIOTIC
}

\author{
Wen-Chin Liu, William L. Parker, Dorothy S. Slusarchyk, \\ Gail L. Greenwood, Susan F. Graham and Edward Meyers \\ The Squibb Institute for Medical Research \\ New Brunswick, New Jersey, U. S. A. 08903
}

(Received for publication July 14, 1970)

\begin{abstract}
Rabelomycin, a new benz $[a]$ anthraquinone antibiotic, has been isolated from fermentation broths of Streptomyces olivaceus ATCC 21,549. It is active against gram-positive microorganisms. Rabelomycin loses water easily when treated with acid. Structures I and III have been proposed for rabelomycin and its dehydration product, respectively.
\end{abstract}

Rabelomycin, a new antibiotic, is produced by a strain of Streptomyces olivaceus ATCG 21,549 isolated from a soil sample taken at Jean-Rabel, Haiti. Structure I has been assigned to rabelomycin on the basis of spectral and chemical studies of the crystalline material.

\section{Fermentation}

Streptomyces olivaceus ATCG 21,549 was isolated from soil by means of the bioautographic technique previously described ${ }^{1)}$. The culture was maintained by storage in liquid nitrogen and, when needed, was grown out on tomato paste-oatmeal agar slants. This medium is made by adding one volume of a boiling aqueous suspension of tomato paste $(4 \%)$ and oatmeal $(4 \%)$ to one volume of a boiling aqueous solution of agar $(3 \%)$.

The growth from well-sporulated slants was suspended in $0.01 \%$ sodium lauryl sulfate and used to inoculate the germinator medium, which had the following composition :

$\begin{array}{lllc}\text { Soybean meal (Staley's 4S) } & 15.0 \mathrm{~g} & \mathrm{CoCl}_{2} \cdot 2 \mathrm{H}_{2} \mathrm{O} & 0.005 \mathrm{~g} \\ \text { Dehydrated mashed potato } & 15.0 & \mathrm{CaCO}_{3} & 10.0 \\ \text { Glucose } & 50.0 & \mathrm{Agar} & 2.5\end{array}$

Distilled water to $1,000 \mathrm{ml}$

After 96 hours of incubation at $25^{\circ} \mathrm{C}$ on a rotary shaker, the growth was used to provide inoculum for fermentation vessels containing the same medium, except that the concentrations of soybean meal and glucose per $1,000 \mathrm{ml}$ were 30.0 and $15.0 \mathrm{~g}$, respectively. The fermentation was harvested after $72 \sim 96$ hours at $25^{\circ} \mathrm{C}$.

The progress of the fermentation, as well as the subsequent steps during isolation, was followed by several bioassay techniques with Staphylococcus aureus FDA 209P as the indicator organism: twof old tube dilution assay, paper disc-agar diffusion assay, and bioautography of thin-layer chromatograms. Two solvent systems for thin-layer 
chromatography on silica gel were normally employed: a) chloroform-methanolpiperidine ( $94: 5: 1$ by volume) and b) benzene-methanol ( $9: 1$ by volume). Rabelomycin had an $\mathrm{Rf}$ of 0.4 in the first system and of 0.5 in the second.

\section{Isolation and Purification}

At harvest, the $\mathrm{pH}$ of the fermentation beer was adjusted to 6.0 , the beer was filtered, and the filtrate (190 liters) was extracted with three 70-liter portions of ethyl acetate. Concentration of the extract in vacuo gave $400 \mathrm{~g}$ of a syrup. A $100-\mathrm{g}$ portion of the concentrate was processed by counter-current distribution in a methanolwater-hexane system ( $3: 1: 4$ by volume), employing six $500-\mathrm{ml}$ separatory funnels with $200 \mathrm{ml}$ each of upper and lower phases per funnel. A total of 12 transfers was made, moving the lower phase. Antibiotic activity was found in the first four fractions of the mobile phase, whereas the oily impurities remained in the upper phase of the first two funnels.

The active fractions were combined and concentrated to remove the organic solvents. Extraction of the resulting mixture with ethyl acetate, followed by concentration of the extract, gave $30 \mathrm{~g}$ of dry residue. A $10-\mathrm{g}$ portion of this material was then dissolved in $20 \mathrm{ml}$ of methanol and placed on a DEAE-cellulose column, packed with $40 \mathrm{~g}$ of Cellex-D (Bio-Rad Laboratories, Richmond, Galifornia) in methanol. The column was developed with methanol and $20-\mathrm{ml}$ fractions were collected. The active fractions were combined and concentrated to dryness, yielding $1 \mathrm{~g}$ of powder. At this point, the bulk of the impurities had been removed from the active material. Further purification was effected by preparative thin-layer chromatography on silica gel plates $(1,000-\mu$ layer $)$, using $10 \%$ methanol in benzene. After development, the active material, appearing as a yellow band, was removed from the plate and eluted with acetone. Chromatography was usually repeated before the compound would crystallize readily. The yield was $c a .70 \mathrm{mg}$. Recrystallization from a benzene-methanol mixture gave yellow needles.

\section{Characterization}

Crystalline rabelomycin melts with decomposition at $193^{\circ} \mathrm{C}$ in an evaculated capillary. It is soluble in ethanol, acetone, and chloroform, and insoluble in water and petroleum ether. The following instrumentation was used for characterization: Perkin-

Fig. 1. Infrared spectrum of rabelomycin $(\mathrm{KBr})$.

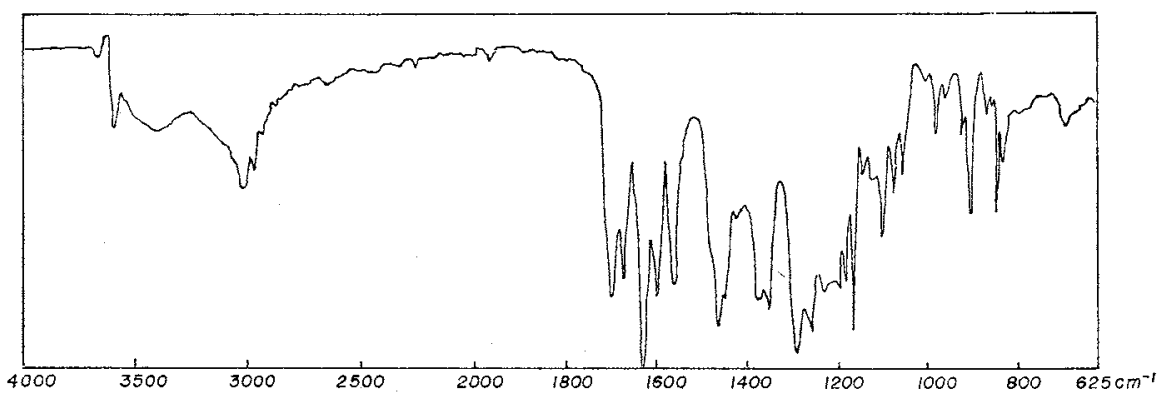


Fig. 2. NMR spectrum of rabelomycin.

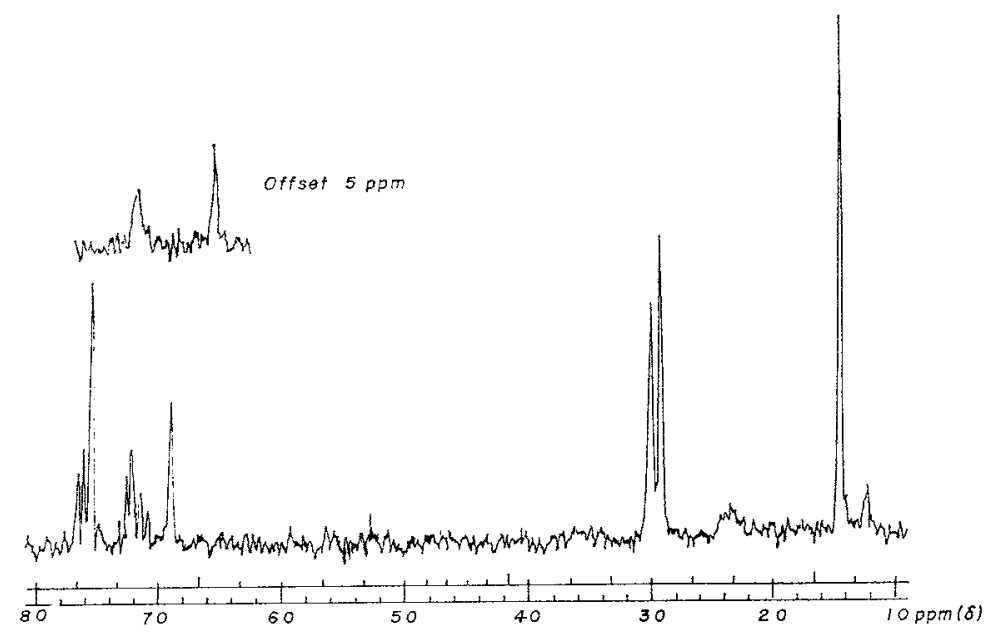

Elmer Model 257 infrared spectrophotometer, Perkin-Elmer Model 402 ultraviolet spectrophotometer, Perkin-EImer Model 141 polarimeter, Varian T-60 nmr spectrometer, and AEI Model MS-9 mass spectrometer. The infrared spectrum $\left(\mathrm{CHCl}_{3}\right)$ is shown in Fig. 1. The nmr spectrum (Fig. 2) was measured in $\mathrm{CDCl}_{3}$ using tetramethylsilane as an internal standard: $\delta 1.47(\mathrm{~s}, 3), 2.37$ (broad, 1), $2.98(\mathrm{~s}, 2), 3.06(\mathrm{~s}, 2), 6.92(\mathrm{~s}, 1), 7 \sim 8$ $(\mathrm{m}, 3), 11.60(\mathrm{~s}, 1)$, and $12.21 \mathrm{ppm}(\mathrm{s}, 1)$; uv $\max$ (neutral and acidic methanol): 228 $\mathrm{nm}(\varepsilon 26,600), 267(28,800), 433(8,000)$; uv $\max$ (basic methanol) $258 \mathrm{~nm}(\varepsilon 26,200)$; sh $282(13,100), 325(8,900), 507(7,500) ;[\alpha]_{D}-102 \pm 10^{\circ}\left(c 1.0\right.$ in $\left.\mathrm{CHCl}_{3}\right)$. The high-resolution mass spectrum showed that the composition of the molecular ion $(\mathrm{m} / \mathrm{e} 338)$ is $\mathrm{C}_{19} \mathrm{H}_{14} \mathrm{O}_{8}$.

$$
\begin{aligned}
& \text { Anal. Calcd. for } \mathrm{C}_{19} \mathrm{H}_{14} \mathrm{O}_{6} \text { : C 67.45, H 4.17. } \\
& \text { Found: C } 67.17, \mathrm{H} 4.48 \text {. }
\end{aligned}
$$

\section{Biological Properties}

Rabelomycin is active against grampositive microorganisms; its in vitro antibacterial spectrum is shown in Table 1. These results are similar to those reported for tetrangomycin ${ }^{2)}$.

\section{Discussion}

The characterization data for rabelomycin indicate that it is a close relative of
Table 1. In vitro antibacterial activity of rabelomycin

\begin{tabular}{l|c}
\hline \multicolumn{1}{c|}{ Microorganism } & $\begin{array}{c}\text { M.I.C } \\
(\mu \mathrm{g} / \mathrm{mi})\end{array}$ \\
\hline Staphylococcus aureus FDA 209P & 6.3 \\
Streptococcus pyogenes C 203 & 1.2 \\
Bacillus subtilis ATCC 6633 & 4.7 \\
Escherichia coli ATCC 10536 & $>50.0$ \\
Salmonella schottmuelleri SC 3850* & $>50.0$ \\
Pseudomonas aeruginosa SC 3840* & $>50.0$ \\
Candida albicans CBS 35 H & $>50.0$ \\
Trichophyton mentagrophytes SC $2637^{*}$ & $>50.0$ \\
\hline
\end{tabular}

* Squibb culture collection tetrangomycin, II, an unusual type of antibiotic recently reported ${ }^{2,3)}$. Indeed, the nmr spectra of the two compounds only differ significantly in that the spectrum of rabelomycin has one additional chelated hydroxyl peak (11.60 ppm) and absorption in the aromatic region for one less proton. The multiplet in the 7 to $8 \mathrm{ppm}$ region is consistent with a three-proton system expected for ring $\mathrm{A}$, while the singlet at $6.92 \mathrm{ppm}$ indicates an isolated proton on ring $C$. The empirical formula of rabelomycin differs from that of tetrangomycin by the addition of one oxygen atom. Attachment of a hydroxyl group on 
ring $\mathrm{C}$, adjacent to the carbonyl group, gives a structure, I, (3, 4-dihydro-3, 6, 8-trihydroxy-3-methylbenz [a] anthracene-1,7,12(2) -trione) that is consistent with the differences between the nmr spectra for rabelomycin and tetrangomycin. The interpretation of the rest of the spectrum is the same as that given for the nmr spectrum of tetrangomycin ${ }^{3)}$.

The nmr spectrum alone does not establish I unambiguously as the structure for rabelomycin, but structural<smiles></smiles>
relationships provided by other spectroscopic methods eliminate alternative structures. The carbonyl absorption in the infrared spectrum (Fig. 1) shows that only one of the quinone carbonyls is chelated ${ }^{4)}$. Also, the absorption at $1700 \mathrm{~cm}^{-1}$, assigned to the carbonyl group on ring $\mathrm{D}$, is at a somewhat unusual frequency due to steric and electronic interactions with the quinone carbonyl group, as had been observed for tetrangomycin ${ }^{3)}$. While splitting between the proton on ring $\mathrm{C}$ and the neighboring methylene group of ring $\mathrm{D}$ is not observed directly, coupling can be demonstrated by double resonance: irradiation of the absorption at $3.06 \mathrm{ppm}$ gives a pronounced sharpening of the $6.92 \mathrm{ppm}$ resonance. The long-wavelength uv absorption maximum $(433 \mathrm{~nm})$ is, as expected, about the same as that for 1,8 -dihydroxyanthraquinone $(432 \mathrm{~nm})^{5)}$. The proposed location of the oxygen function on ring $\mathrm{C}$ is consistent with biogenesis from a hypothetical poly- $\beta$-ketomethylene precursor.

Rabelomycin is readily dehydrated to 1,6,8-trihydroxy3-methylbenz [a] anthracene-7,12-dione, III, either thermally or by treatment with acid. To prepare III, a sample of rabelomycin was dissolved in concentrated sulfuric acid, giving a blood-red solution. Water was added with stirring, followed by extraction of III from the mixture with ethyl acetate. Purification by chromatography on silica gel, eluting with ethyl acetate-chloroform (1:4), and<smiles>Cc1cc(O)c2c3c(c(O)cc2c1)C(=O)c1c(O)cccc1C3=O</smiles>
recrystallization from ethyl acetate gave a dark green solid: m.p. $204.5 \sim 205.0^{\circ} \mathrm{C}$ (evacuated capillary); ultraviolet max (neutral and acidic methanol): $234 \mathrm{~nm}(\varepsilon 39,9000), 268(13,400)$, $325(14,000), 455(7,500)$, sh $550(2,050)$; uv $\max$ (basic methanol) : $235 \mathrm{~nm}(\varepsilon 38,800), 309$ $(15,200), 555(8,300)$; infrared $(\mathrm{KBr}) 1632,1607 \mathrm{~cm}^{-1} ; \mathrm{nmr}\left[\mathrm{CF}_{3} \mathrm{CO}_{2} \mathrm{H}-\mathrm{H}_{2} \mathrm{SO}_{4}(10: 1)\right] \delta \mathrm{ca}$. 1.2 (broad, 3), $2.54(\mathrm{~s}, 3), 4.40(\mathrm{~s}, 2), 7.05(\mathrm{~s}, 1), 7.2 \sim 8.5 \mathrm{ppm}(\mathrm{m}, 4)$. (The solvent peak was used as an internal standard and was taken to be $11.30 \mathrm{ppm}$ downfield from tetramethylsilane.) The high-resolution mass spectrum showed that the molecular ion (m/e 320$)$ was $\mathrm{C}_{19} \mathrm{H}_{12} \mathrm{O}_{5}$.

\section{Anal. Cald. for $\mathrm{C}_{19} \mathrm{H}_{12} \mathrm{C}_{5}$ : C 71.24, $\mathrm{H} 3.78$.}

Found: C 71.34, H 4.08 .

Rabelomycin is rather stable in glacial acetic acid, but was partially converted to III when a dilute solution in benzene was shaken with concentrated $\mathrm{HCl}$ for 3 minutes. In samples of rabelomycin that had been melted, III could easily be detected by thin-layer chromatography. However, unlike tetrangomycin ${ }^{3)}$, rabelomycin is not dehydrated by dilute base, perhaps because of the concentration of hydrogen bonds that would make rabelomycin more acidic. As a phenolate anion, it would be less subject to attack by base on ring $D$. The infrared spectrum of III shows that both carbonyl groups are chelated, supporting the structural relationship in rabelomycin between the carbonyl group of ring $\mathrm{D}$ and the carbonyl group that is not intramolecularly hydrogen bonded.

The nmr data for III in trifluoroacetic acid-concentrated sulfuric acid (10:1) (used for solubility reasons) indicate that III is protonated on ring D by the solvent. Similar behaviour has been observed for other aromatic systems in strong acid ${ }^{6)}$. The broad peak at $1.2 \mathrm{ppm}$ may be due to impurities. Phenolic protons are generally not observed in acid solvents ${ }^{7}$ and we failed to observe the phenolic protons of phloroglucinol in this particular 
solvent system. In nmr spectra of III taken in methylene chloride and in tetrahydrofuran, the phenolic protons absorb at about $12.0,11.7$ and $10.3 \mathrm{ppm}$. The latter peak is probably due to the ring $\mathrm{D}$ hydroxyl proton, which is chelated as expected ${ }^{8)}$.

The structure of another antibiotic, aquayamycin, having the unusual benzanthraquinone. system has recently been reported ${ }^{9}$.

\section{Acknowledgements}

We thank Mr. J. Auicino for elemental analyses, Dr. A. Cohen for mass spectra, Mr. H. I. Basch for in vitro assays, Mr. W. H. TREJo for identification of the culture, Dr. B. BERK and his colleagues for tank fermentations and Dr. H. ConDs and his colleagues for the initial isolation steps.

\section{References}

1) Meyers, E.; D. A. Smith \& R. Donovick : Bioautographic technique for a rapid survey of microbial populations for the production of antibiotics and other metabolites. Appl. Microbiol. 16: $10 \sim 12,1968$

2) Dann, M.; D. V. Lefemine, F. Barbatschi, P. Shu, M. P. Kunstmann, L. A. Mitscher \& N. Bomonos: Tetrangomycin, a new quinone antibiotic. Antimicr. Agents \& Chemoth. $-1965: 832 \sim 835,1966$

3) Kunstmann, M. P. \& L. A. Mrtscher: The structural characterization of tetrangomycin and tetrangulol. J. Org. Chem. $31: 2920 \sim 2925,1966$

4) Nakanishi, K. : Infrared Absorption Spectroscopy, Practical. p. 43, Holden-Day, San Francisco, 1962

5) Morton, R. A. \& W. T. EARlam : Absor ption spectra in relation to quinones : 1, 4-naphthaquinone, anthraquinone, and their derivatives. J. Chem. Soc. 1941: 159 169, 1941

6) Jackman, L. M. \& S. Sternhelu : Applications of Nuclear Magnetic Resonance Spectroscopy in Organic Chemistry, 2nd ed, p. 254, Pergamon, Oxford, 1969

7) Brrchall, T.; A. N. Bourns, R. J. Gillespie \& P. J. Smith : Nuclear magnetic resonance studies: of the protonation of weak bases in fluorosulphuric acid. Canad. J. Chem. $42: 1433 \sim 1439,1964$

8) Ref. 6, p. 216

9) Hayashi, O.; S. Okuno, H. Fujisawa \& H. Umezawa: Inhibition of brain tryptophan 5-monooxygenase by aquayamycin. Biochem. Biophys. Res. Comm. 39:643 650, 1970 